\title{
Anionic polymerization of various methacrylates initiated with LiCI- complexed sBuLi
}

\author{
S. Antoun, J. S. Wang, R. Jérôme and Ph. Teyssié \\ Center for Education and Research on Macromolecules (CERM), University of Liège, Sart- Tilman B6, 4000 \\ Liège, Belgium
}

\begin{abstract}
A simple alkyl lithium initiator (sBuLi) complexed with $\mathrm{LiCl}$ (10 molar equiv.) has been used to initiate the anionic polymerization of various methacrylic monomers, i.e. methyl methacrylate (MMA), tert-butyl methacrylate (tBuMA), glycidyl methacrylate (GMA), and dimethyl amino ethyl methacrylate (DMAEMA) in tetrahydrofuran at $-78^{\circ} \mathrm{C}$. Only the homopolymerization of tBuMA proceeds in a living manner, as evidenced by both the linear plot of experimental molecular weight $\left(M n_{\text {exp }}\right)$ vs theoretical ones $\left(M n_{\text {cal }}\right.$ ) (slope $\left.\sim=0.93\right)$ and monomer resumption experiments. However, three types of block copolymers, i.e. PtBuMA-b-PMMA, PtBuMA-b-PGMA, PtBuMA-b-PDMAEMA, have been successfully synthesized with a predictable molecular weight, and narrow molecular weight distribution.
\end{abstract}

Keywords: alkyl methacrylate; anionic polymerization; set-butyl lithium)

\section{Introduction}

LiCl-modified organolithium initiators have been proven to effectively induce a perfectly 'living' anionic polymerization of (meth)acrylates at low temperature ${ }^{1-3}$. To avoid undesirable side reactions in the initiation step, the use of highly delocalized and sterically hindered initiators, such as diphenyl methyl lithium (DPMLi), 1,1diphenyl hexyl lithium (DPHLi), or oligomeric $\alpha$-methyl styryl lithium ( $\alpha$-MStLi $\mathrm{Li}^{+}$), were strongly recommended ${ }^{4}$. However,Varshney et al. have reported that LiCl-complexed set-butyl lithium can afford wellcontrolled poly(tert butyl acrylate) oligomers ${ }^{5}$.

On the other hand, we have been recently interested in the investigation of liquid state solution properties of micelle-forming (meth)acrylates (co)polymers by means of fluorescence spectroscopy. In fact this powerful methodology allows monitoring of the take up and release of small hydrophobic molecules as well as of the properties of the micelles themselves. Such methods are becoming increasingly important tools for the study of nano-environmental phenomena ${ }^{6}$. However, it has been found that even the presence of one single aromatic group per polymer chain may cause additional absorption and consequently blur the expected fluorescence signal. That is the reason why attention is now being paid to the possibility of synthesizing well-controlled poly(meth)acrylate-based homo- and block-copolymers by using aromatic group free initiator systems. In this paper we present some preliminary results about the anionic polymerization of several interesting methacrylates, i.e. methyl methacrylate (MMA), tert-butyl methacrylate (tBuMA), glycidyl methacrylate GMA), dimethyl amino ethyl methacrylate (DMAEMA), by using a simple alkyl lithium compound sBuLi as initiator, and $\mathrm{LiCl}$ as ligand. Moreover, three types of block copolymers have also been prepared, which can all be converted into amphiphilic products.

\section{Results}

Table I illustrates the characteristic features of anionic polymerization of various methacrylates, i.e. GMA, DMAEMA, tBuMA, in tetrahydrofuran (THF) at $-78^{\circ} \mathrm{C}$ by using a simple alkyl lithium initiator (i.e. $\mathrm{sBuLi}$ ) in the presence of 10 molar equivalents of $\mathrm{LiCl}$. Although it has been reported that aromatic type initiators are very effective in promoting a 'living' anionic polymerization of methacrylates ${ }^{3.7-9}$, Table 1 shows that use of a simple alkyl lithium, sBuLi, under otherwise the same experimental conditions, gives rise to completely ill-controlled products even at very low yields $(<10 \%)$. It was also found that the final products are not soluble in THF. It is well-known that this simple alkyl initiator displays a high nucleophilicity and low steric hindrance compared to the aromatic ones, and that side termination reactions are often found to occur at the initiation stage ${ }^{10}$. The present results might thus strongly suggest that the $\mu$-complexation of this simple alkyl lithium initiator by $\mathrm{LiCl}$ cannot afford the expected beneficial effects for the anionic polymerization of these methacrylates.

As far as tBuMA is considered, the polymerization process becomes much better controlled even in the absence of LiCl. As shown in Table 1, tBuMA anionic polymerization in $\mathrm{THF}$ at $-78^{\circ} \mathrm{C}$ gives rise to a quantitative yield. However, a bimodal distribution was still clearly noted (Figure I), with a molecular weight distribution (MWD $\mathrm{M}_{\mathrm{w}} / \mathrm{M}_{\mathrm{n}} \sim=1.45$ ) probably indicating the occurrence of some side reactions. In sharp contrast to these results, 
however, the use of 10 molar equivalents of $\mathrm{LiCl}$ versus $\mathrm{sBuLi}$ induces a precisely controlled PtBuMA with an initiator efficiency very close to $1(f=0.95)$ and narrow MWD $\left(\mathrm{M}_{\mathrm{w}} / \mathrm{M}_{\mathrm{n}}=1.06\right)$, suggestive of a living process. In order to confirm that preliminary conclusion, a series of tBuMA anionic polymerizations were carried out in $\mathrm{THF}$ at $-78^{\circ} \mathrm{C}$ using various monomer/initiator molar ratios, and a constant $\mathrm{LiCl} / \mathrm{sBuLi}$ molar ratio of 10 . As clearly illustrated in Figure 2. a linear plot of theoretical molecular weight $\left(\mathrm{Mn}_{\mathrm{n} \text { cal }}\right)$ versus the experimental one $\left(\mathrm{M}_{\mathrm{n} \text { s.e.c. }}\right)$ is obtained in a molecular weight range from 5000to 200000 with a slope of 0.93 , in good agreement with the initiator efficiency reported in Table $1(f=0.95)$.

Further evidence for the living tBuMA anionic polymerization was provided by two step monomer resumption experiments. Accordingly, a first dose of tBuMA $\left(1.9 \times 10^{-2} \mathrm{~mol}\right)$ was polymerized $\left([\mathrm{sBuLi}]=9.1 \times 10^{-3} \mathrm{~mol}^{-1}\right)$ the experimental molecular weight of which was found to be very close to the theoretical one $(f=0.91)$; at the same time the MWD is very narrow $(=1.1)$; $3 \mathrm{~h}$ later the second dose of monomers $\left(2.34 \times 10^{-2} \mathrm{~mol}\right)$ was introduced again to the above living solution and polymerization was continued for another $3 \mathrm{~h}$. As a result, size exclusion chromatography (s.e.c.) clearly shows that practically no first dose PtBuMA contaminates the final product (Figure 3), and that the experimental molecular weight $\left(M_{n \text { s.e.c. }} \sim=5.54 \times 10^{-3}\right)$ is again very close to the calcu-latedone $\left(\mathrm{M}_{\mathrm{nca}} \mathrm{l} \sim=5.11 \times 10^{3}\right)$ with $\mathrm{MWD}=1.09$. At this point, one may safely state that LiCl-complexed $\mathrm{sBuLi}$ can induce a perfectly living polymerization of tBuMA in $\mathrm{THF}$ at $-78^{\circ} \mathrm{C}$.

Furthermore, an attempt was also devoted to the synthesis of aromatic group-free block copolymers. In that prospect, tBuMA-containing blocks were first prepared through above-mentioned procedures, and followed by addition of other methacrylates, i.e. MMA, GMA, DMAEMA, into living PtBuMA Li ${ }^{+} / 1 \mathrm{O}$ LiCl solution. As demonstrated in Table 2, predicted

Further evidence for the living tBuMA anionic polymerization was provided by two step monomer resumption experiments. Accordingly, a first dose of $\operatorname{tBuMA}\left(1.9 \times 10{ }^{\mathrm{I}} \mathrm{mol}\right)$ was polymerized $\left([\mathrm{sBuLi}]=9.1 \times 1 \mathrm{lo}^{--} \mathrm{mol}^{-1}\right)$ the experimental molecular weight of which was found to be very close to the composition and molecular weight are observed for these copolymers. Also, within experimental error, there is no homo-tBuMA showing up in the s.e.c. diagrams (Figure 4). i.e. pure block copolymers are now prepared. Although these three types of block copolymers have been prepared using DPHLi or crMStLi as initiator by other workers ${ }^{3} .^{7-9}$, the present work does show that they can also be prepared by LiCl-complexed aromatic group-free simple organolithium initiators.

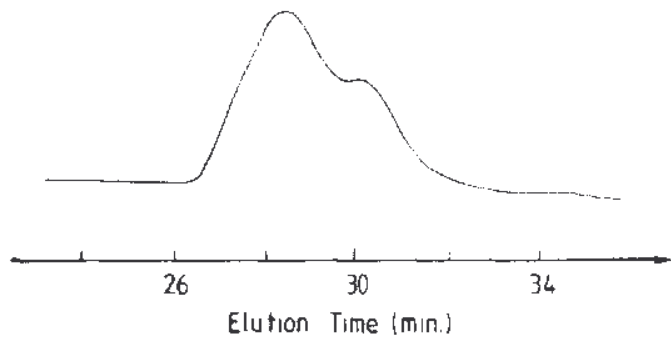

Figure 1 S.e.c. of PtBuMA synthesized amonically $\mathrm{m}$ THF at $-78^{\circ} \mathrm{C}$ without $\mathrm{LiCl}$ using sBuLi as initiator

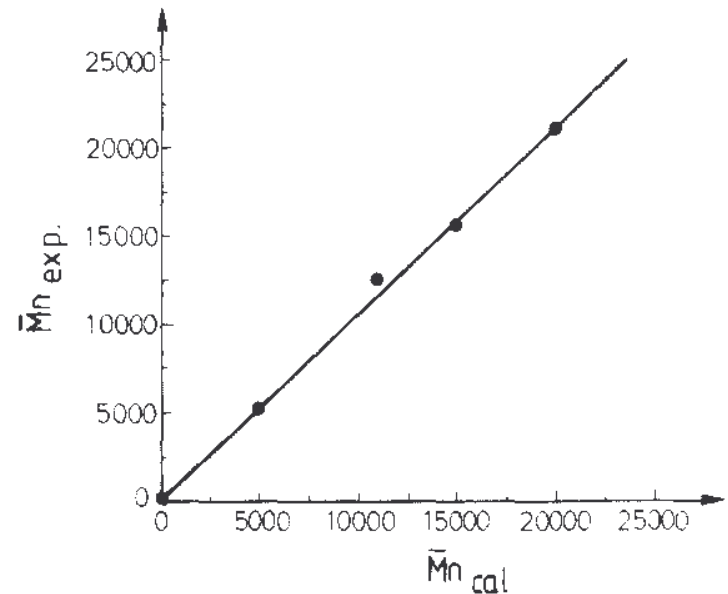

Figure 2 Plot of calculated $M n$ vs experimental values obtained from s.e.c., slope $=0.93$ 
Published in: Polymer (1996), vol. 37, iss. 25, pp. 5755-5759

Status: Postprint (Author's version)

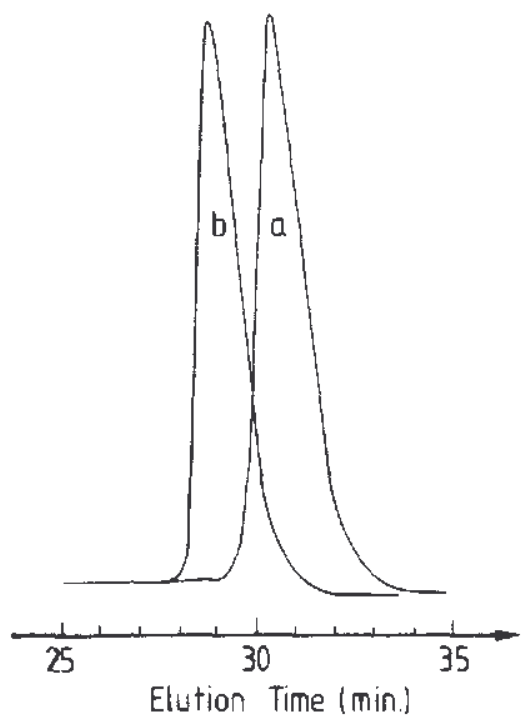

Figure 3 S.e.c. chromatograms of PtBuMA produced at $-78^{\circ} \mathrm{C}$ by polymertzation of one (a) and two (b) aliquots of tBuMA initiated by 10 $\mathrm{LiCl} / \mathrm{sBuLi}$ (the second aliquot added $3 \mathrm{~h}$ after the first) 
Table 1 Anionic polymerization of methacrylates in THF at $-78 \mathrm{C}$ using $10 \mathrm{LiCl}$ sBuLi as the initiator system

\begin{tabular}{|c|c|c|c|c|c|c|c|c|}
\hline \multirow[t]{9}{*}{$\begin{array}{l}\text { Published } \\
\text { Status: } P_{1}\end{array}$} & Monomer & $\underset{(m a l i]}{\text { sBuLi }]} \times$ & $\begin{array}{l}\text { Time: } \\
\text { (h) }\end{array}$ & $\begin{array}{l}\text { Yield } \\
\left(w t_{0}\right)\end{array}$ & $M_{\mathrm{b}, \mathrm{i}} \times 10^{3 h}$ & $\begin{array}{l}M_{\mathrm{n}} \times 10^{-3} \\
\text { is.e.c.) }\end{array}$ & $M_{w} / M_{n}{ }^{\prime \prime}$ & $f^{d t}$ \\
\hline & $\mathrm{MMA}$ & 8.33 & 1.5 & 4 & $\therefore$ & & & \\
\hline & $\mathrm{GMA}$ & 3.75 & 1.5 & 3 & $\therefore$ & & -- & \\
\hline & tBuMA & 9.1 & 4 & & 2.45 & 2.69 & 1.1 & 0.91 \\
\hline & IBuMA & 9.1 & 4 & quantitative & 5.11 & 5.54 & 1.09 & 0.92 \\
\hline & tBuMA & 2.57 & + & yuantitative & 17.86 & 19.08 & 1.02 & 0.94 \\
\hline & tBuMA $A^{e}$ & 9.5 & 2 & 99 & 5.0 & 7.24 & 1.45 & 0.69 \\
\hline & \multicolumn{8}{|c|}{ "Gravimetrically } \\
\hline & \multicolumn{8}{|c|}{${ }^{b} M_{\mathrm{n}}=\frac{\text { weight of monomer }}{\text { moles of initiator }} \times \mathrm{wt}^{0} \%$ conk. } \\
\hline
\end{tabular}

Table 2 Characterization of block copolymers PtBuMA-b-PMMA; PtBuMA-b-PGMA; PtBuMA-b-PDMAEMA, anionically synthesized in THF at $-78^{\circ} \mathrm{C}$ using 10 LiCl/sBuLi as the initiator system ${ }^{a}$

\begin{tabular}{|c|c|c|c|c|c|c|c|c|c|c|}
\hline \multirow[b]{2}{*}{ Number } & \multirow[b]{2}{*}{ Copolymers } & \multirow{2}{*}{$\begin{array}{l}\text { Theoretical } \\
\text { composition } \\
\text { (wt \% tBuMA) }\end{array}$} & \multicolumn{2}{|c|}{$M_{n} \times 10^{-3}$ PtBuMA } & \multirow[b]{2}{*}{$\begin{array}{l}M_{\mathrm{w}} / M_{\mathrm{n}}^{c} \\
\text { (PtBuMA) }\end{array}$} & \multirow{2}{*}{$\begin{array}{l}\text { Total } \\
\text { conversion } \\
(w t \%)\end{array}$} & \multicolumn{2}{|c|}{$\begin{array}{c}M_{\mathrm{n}} \times 10^{-3} \text { block } \\
\text { copolymers }\end{array}$} & \multirow[b]{2}{*}{$M_{\mathrm{w}} / M_{\mathrm{n}}{ }^{\mathrm{N}}$} & \multirow{2}{*}{$\begin{array}{l}\text { tBuMA } \\
\text { content in } \\
\text { copolymer }\end{array}$} \\
\hline & & & Theoretical $^{b}$ & $\begin{array}{l}\text { Experimental } \\
\text { (s.e.c.) }\end{array}$ & & & Theoretical $^{d t}$ & $\operatorname{Exp}^{e}$ & & \\
\hline 1 & IBuMA- $b$-MMA & 75 & 5 & 4.77 & 1.06 & 97 & 5.82 & 6.4 & 1.08 & 74 \\
\hline 2 & tBuMA-b-GMA & 25 & 3 & 3.68 & 1.08 & quantitative & 14.1 & 13.6 & 1.06 & 27 \\
\hline 3 & tBuMA-b-DMAEMA & 25 & 3 & 3.28 & 1.09 & quantitative & 13.8 & 13.66 & 1.11 & 24 \\
\hline
\end{tabular}

${ }^{a}$ Polymerization of tBuMA, $4 \mathrm{~h}$ at $-78^{\circ} \mathrm{C}$, copolymerization of MMA, GMA, DMAEMA, $1.5 \mathrm{~h}$ at $-78^{\circ} \mathrm{C}$, polymer concentration $\approx 5 \%$

${ }^{b} M_{\mathrm{n}_{\mathrm{bal}}}=\frac{\text { weight of reacted monomer (g) }}{\text { mole of initiator }}$

${ }^{c}$ S.e.c. value

${ }^{d} M_{\mathrm{n}}$ copolymers $=\frac{\text { weight } \text { of monomers }(\mathrm{g})}{\text { mole of }} \times \mathrm{wt} \%$ conversion

${ }^{e} M_{\mathrm{n}}$ copolymers $=-M_{\mathrm{n}}$ first block (s.e.c. value)

${ }^{f}$ By 'H n.m.r. analysis 


\section{Discussion}

As already demonstrated elsewhere ${ }^{11}$. when a highly charge-delocalized and sterically hindered initiator is used even without any added ligand, the anionic polymerization of alkyl methacrylates in THF at low temperatures may become a living process. The failure of a simple alkyl organolithium initiator in promoting that living process might thus well be due to a combination of its small size and very strong nucleophilicity ${ }^{10}$.

Conversely. it has been already demonstrated by us that the complexation of alkali-metal containing initiators by $\mathrm{LiCl}$ offers an efficient pathway to diminish the potential side termination reactions between initiator and (meth)acrylic ester monomer and polymer ${ }^{1-5}$. For instance, although polymerization of MMA or tBuA initiated with poly(styry1 lithium) (PSt $\mathrm{Li}^{+}$) macro-anions always leads to definite amounts of homo-PSt present, due to the violent attack of ester groups in $(\mathrm{P}) \mathrm{MMA}$ or $(\mathrm{P}) \mathrm{tBuA}$ by rather basic $\mathrm{PSt}^{-} \mathrm{Li}+$ species, the $\mathrm{LiCl}$-complexed PSt- $\mathrm{Li}^{+}$can effectively give rise to pure PSt-b-PMMA or PSt-b-PtBuA block copolymers under otherwise the same experimental conditions ${ }^{12}$. Obviously, the present work now provides an additional evidence for the high efficiency of $\mathrm{LiCl} \mu$-ligand in protecting from noxious reactions the polymerization of at least tBuMA initiated with a simple alkyl lithium initiator. The fact that other small and functional esters studied here still give rise to deviant secondary reactions might point towards the limit of the protection ensured by the added LiCl ligand against a vigorous nucleophilic attack.

Finally, the successful block copolymerization of these small and functional methacrylates by LiCl-added PtBuMA- $\mathrm{Li}^{+}$may be accounted for by the presence of a significantly lower nucleophilicity of the ester enolate active species (compared to the simple alkyl lithium), which is indeed in good agreement with previously reported findings ${ }^{13}$.

In conclusion, $\mathrm{LiCl}$-complexed simple lithium initiators are very effective in producing a living aromatic-group free homo-PtBuMA and corresponding block copolymers PtBuMA-b-PMMA, PtBuMA-b-PGMA, PtBuMAb,PDMAEMA, a very promising situation since hydrolysis, quaternization or sulfonation of tBuMA, DMAEMA, GMA, respectively, can provide various types of amphiphilic blocks which are currently investigated.

Fluorescence studies of these modified copolymers will be the subject of a forthcoming paper.

Experimental

All the monomers, from Aldrich, were first vacuum distilled from $\mathrm{CaH}_{2}$ and then stored under a nitrogen atmosphere at $-20^{\circ} \mathrm{C}$. Before polymerization, MMA, tBuMA, DMAEMA were added dropwise with a triethyl aluminium solution in hexane until a persistent yellowish green colour was observed. GMA was purified as described elsewhere ${ }^{3}$.

$\mathrm{LiCl}$ (99.9\% purity, Aldrich) was dried overnight at $130^{\circ} \mathrm{C}$ in the reactor. THF was purified by refluxing over fresh sodium benzophenone complex and distilled before use over polystyryl lithium.

Initiator solution was transferred under nitrogen atmosphere into a glass containing THF at $-78^{\circ} \mathrm{C}$. After addition of the initiator by syringe, the monomers were added using a capillary-septum technique.

For the block copolymers, an aliquot of the reaction medium was withdrawn for analysis by s.e.c. in order to determine the molecular weight of the first block.

Conversion was determined gravimetrically after polymerization, precipitation in a methanol/water mixture or in heptane in the case of DMAEMA, and through drying. Experimental molecular weights were determined using a Hewlett-Packard 1090 equipped with four columns and polystyrene standards for calibration. THF was used as solvent, although in the case of DMAEMA. $1 \%$ of triethyl amine was added to the system.

'H nuclear magnetic resonance (nmr.) analysis was performed in $\mathrm{CDCl}_{3}$ solution using a $400 \mathrm{MHz}$ Bruker spectrometer.

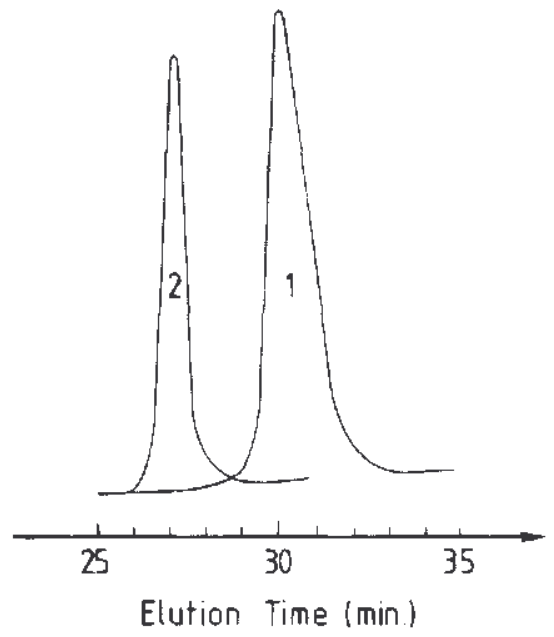

Figure 4 S.e.c. of sample 7. Table 2. (I) PtBuMA. $M n=3680 . M w / M n=1.08$; (2) block copolymer. $M n=13600 . M w / M n=1.06$ prepared in $\mathrm{THF}$ at $-78^{\circ} \mathrm{C}$ using $10 \mathrm{LiCl} / \mathrm{sBuLi}$ complexed initiator 


\section{A cknowledgement}

The authors are very grateful to the Services Federaux des Affaires Scientifiques, Techniques et Culturelles', for support in the frame of the 'Poles d'Attraction Inter-universitaires: Polymires'.

\section{References}

1 Jérôme. R.. Forte. R.. Varshney. S. K., Fayt. R. and Teyssie. Ph. in 'Recent Advances in Mechanistic and Synthetic Aspects of Polymerization' (Eds M. Fontanille and A. Guyot). NATO Advanced Study Institute Series C215. Plenum. New York 1987. p. 101

2 Teyssie, Ph.. Varshney, S. K., Jérôme, R. and Fayt, R. Eur. Patent 87402893.9 (1987): US Patent 4,826,941 (2 May. 1989)

3 Leemans, L., Fayt, R. and Teyssie, Ph. .I. Polym. Sci., Polym. Chem. Edn 1990. 28. 2187

4 Teyssie Ph., Fayt, R., Hantekeer, J. P., Jacobs, C.. Jerome. R.. Lee-mans. L. and Varshnev. S. K. Makromol. Chem.. Macromol. Svmp. 1990. 32, 61

$5 \quad$ Varshney S. K.. Fayt. R. and Jerome, R. Macromolecules 1992. 25. 5578

6 Ledwith, A. Pure Appl. Chem. 1982, 54, 549; Duhamel, J., Mitchell, A. and Winnik, M. A. Macromolecules 1993, 26,621

7 Creutz, S., Jerome, R. and Teyssii, Ph. unpublished results

8 Long, T. E., Allen, R. D. and McGrath, J. E. ACS Polym. Prepr. 1986, 27(2), 54

9 Hild, G., Lamps, J. P. and Rempp, P. Polymer 1993, 34, 287510 Hatada, K., Kitayama, T., Onta, K. and Yuki, H. 'Anionic

Polymerization: Kinetics, Mechanisms and Synthesis (Eds. J. E. McGrath), ACS Symposium Series, Washington, DC, 1981, p. 327

11 Long, T. E., Allen, R. D. and McGrath, J. P. in 'Recent Advances in Mechanistic and Synthetic Aspects of Polymerization' (Eds M.

Fontanille and A. Guyot), NATO ASI Series C215, 1987, p. 79

12 Hautekeer, J. P., Fayt, R., Jacobs, C., Jerome, R. and Teyssie, Ph. Macromolecules 1990, 23, 3893

13 Wang, J. S., Jerome, R. and Teyssit, Ph. J. Phys. Org. Chem. 1995,8 , 208 